\title{
Population density modulates insect progenitive plasticity through the regulation of dopamine biosynthesis
}

\author{
Kai Liu \\ Sun Yat-Sen University \\ Longyu Yuan \\ Sun Yat-Sen University \\ Lei Yue \\ Sun Yat-Sen University \\ Weiwen Chen \\ Sun Yat-Sen University \\ Kui Kang \\ Sun Yat-Sen University \\ Jun Lv \\ Sun Yat-Sen University \\ Wenqing Zhang \\ Sun Yat-Sen University \\ Rui Pang ( $\triangle$ pr839@163.com ) \\ Sun Yat-Sen University https://orcid.org/0000-0001-9300-6142
}

\section{Research Article}

Keywords: Brown planthopper, Fecundity, Population density, Genotype, Dopamine biosynthesis

Posted Date: February 24th, 2021

DOl: https://doi.org/10.21203/rs.3.rs-215638/v1

License: (c) (i) This work is licensed under a Creative Commons Attribution 4.0 International License.

Read Full License

Version of Record: A version of this preprint was published at Insect Science on March 1st, 2022. See the published version at https://doi.org/10.1111/1744-7917.13019. 


\section{Population density modulates insect progenitive plasticity through the regulation of}

\section{dopamine biosynthesis}

Kai Liu ${ }^{1,2} \cdot$ Longyu Yuan ${ }^{1} \cdot$ Lei Yue ${ }^{1} \cdot$ Weiwen Chen $^{1} \cdot$ Kui Kang ${ }^{1} \cdot J^{\prime}$ Lv $^{1} \cdot$ Wenqing Zhang $^{1} \cdot$ Rui Pang ${ }^{1,3}$

${ }^{1}$ State Key Laboratory of Biocontrol, School of Life Sciences, Sun Yat-sen University, Guangzhou 510275, China

${ }^{2}$ Innovative Institute for Plant Health, College of Agriculture \& Biology, Zhongkai University of Agriculture and Engineering, Guangzhou 510225, China

3 Guangdong Provincial Key Laboratory of Microbial Safety and Health, State Key Laboratory of Applied Microbiology Southern China, Institute of Microbiology, Guangdong Academy of Sciences, Guangzhou 510070, China

\section{Correspondence}

Wenqing Zhang, Email: 1sszwq@mail.sysu.edu.cn; Rui Pang, Email: pr839@163.com.

\section{Abstract}

Insect fecundity is a quantitative phenotype strongly affected by genotypes and the environment. However, the interaction between genotypes and the environment factors in modulating the insect fecundity remains largely unknown. In this study, we investigated the density-dependent population dynamics in the brown planthopper (BPH), Nilaparvata lugens, by using two populations respectively carrying homozygous high-fecundity (HFG) and low-fecundity (LFG) genotypes. Under low population densities, the fecundity and population growth rate of the two genotypes showed increasing trends across generations, while the trends between HFG and LFG under high population densities were opposite. RNA-seq was applied to unveil the key factors for these density-dependent progenitive phenotypes. Combined with the temporal analysis and weighted gene co-expression network analysis, we identified two gene modules that simultaneously enriched in four pathways related to the neural system. Among these pathways, the gene Nlpale encoding a tyrosine hydroxylase was identified as the key gene. The RNA interference of this gene and manipulation of its downstream product dopamine could significantly impact the basic and density-dependent 
progenitive phenotypes of BPH. This study shows that the dopamine biosynthesis is the key regulatory factor for the determination of fecundity in response to density changes in different genotypes of $\mathrm{BPH}$, which gives an insight into the interaction of a typical environmental factor and insect genotype during the process of population regulation.

Key works: Brown planthopper $\cdot$ Fecundity $\cdot$ Population density $\cdot$ Genotype $\cdot$ Dopamine biosynthesis

\section{Key Message}

- The interaction of environment factors and genotypes on the fecundity of the brown planthopper Nilaparvata lugens, has not been reported.

- We investigated the density-dependent population dynamics in $N$. lugens by using two populations with high- and low-fecundity genotype.

- Under high population densities, the fecundity and population growth rate of the two genotypes of $N$. lugens showed opposite trends across generations.

- The key gene Nlpale encoding a tyrosine hydroxylase was identified using RNA-seq and bioinformatics analysis.

- RNAi study confirmed the dopamine biosynthesis plays a vital role for the two genotypes of $N$. lugens in response to density changes.

\section{Introduction}

Insects comprise the most diverse class of animals due to their excellent adaptability and high reproductive capacity (Grimaldi and Engel 2005). The reproductive fitness of insects is a quantitative phenotype determined by both of genotypes and the environmental factors. Genotypic factors usually refer to genetic variants that change the function of fecundity-related proteins (Watt 1992; Edward et al. 2014). And environmental factors associated with insect fecundity usually include predators (Rosenheim 1998), temperature (Geister et al. 2008), xenobiotics (Ge et al. 2011), nutrition (Winkler et al. 2006), and the density of insect populations (Stiling 1988). However, how genotypes interact with the environment to modulate the fecundity in a specific insect is largely unknown, due to the lack of appropriate experimental materials. 
Population density acting as a dynamic factor that closely related to insect diet and the available nutrition, has great impact on the population growth of insects (Hassel 1975; Stiling 1988). Population density is critical to the survival and development of the larvae, and consequently impact the fecundity of the emerged adults in a variety of insect species. Aedes aegypti reared in higher larval density showed a greater number of eggs laid (Silva et al. 2020), while Chilo partellus moths at lower pairing density had higher fecundity (Hari et al. 2008). Increased initial density resulted in prolonged nymphal development duration, lower emergence rate, shorter longevity and lower female fecundity in the rice planthopper (Mori and Nakasuji 1991; Horgan et al. 2016). Besides, population density can influence many other processes, such as predator and prey, parasite and host interactions, disease transmission, and competition (Arcese and Smith 1988; Pacala and Hassell 1991; Berg 1992). Thus, the density stress is an ideal factor to study the interaction between insect genotypes and environment during the regulation of population growth.

Previous studies have indicated that population dynamics of insects could be influenced by individual variations (Hanski and Saccheri 2006; Sun et al. 2015). However, it is still a mystery that whether the same population density has equal or diverse impact on insect populations carrying different fitness-determined genotypes. To address this issue, we selected two genotypes of the brown planthopper (BPH), Nilaparvata lugens, a serious rice insect pest. Based on our previous studies, we obtained two homozygous BPH populations [a high-fecundity genotype (HFG) and a low-fecundity genotype (LFG) population] from the same initial population, with the $\mathrm{ACE}_{-862}$ and $\mathrm{VgR}_{-816}$ genotypes $\mathrm{CCGG}$ and AAAA, respectively (Sun et al. 2015; Liu et al. 2020). In this study, we described the population dynamic of the two genotypes BPH in different initial nymph densities by designing a density-dependent experiment. After that, we applied RNA-seq and a series of bioinformatic analysis to unveil the key factors for density-dependent progenitive phenotypes in this insect. Overall, we aimed to uncover the potential mechanisms behind the insect genotypes and population densities interaction in the modulation of insect fecundity.

\section{Materials and methods}

\section{Insect populations and density-dependent bioassays}


The BPH populations carrying homozygous high- (HFG) and low-fecundity (LFG) genotypes were previously obtained in our lab (Zhai et al. 2013; Sun et al. 2015), and were reared on a susceptible rice variety (Fenghuazhan) in the greenhouse at $26 \pm 2{ }^{\circ} \mathrm{C}$ with $70-90 \%$ relative humidity and a light-dark cycle of 16L: 8D h.

$10,50,90,130$ and 170 newly $(<12 \mathrm{~h})$ hatched nymphs of the two BPH populations were individually reared in the 45-day old rice plants, then the rice plants for each treatment were transferred into a pot covered with insect-proof nets. Ten replicative treatments were conducted for each group. The nymphs' development and survival were recorded daily until becoming adults. The rice plants were replaced timely to keep fresh and sufficient for feeding with each treatment. Two-day-old female adults from each treatment were collected for weighting using electronic balance, then placed immediately in liquid nitrogen and stored at $-80^{\circ} \mathrm{C}$ for subsequent transcriptome sequencing. Those planthoppers in the same density treatment were then mate randomly. When nymphs emerged, we count the number of offsprings from each mate until no nymph hatched for three consecutive days. Those newly emerged nymphs taken from corresponding density treatment were used to conduct the same density-dependent bioassays as the next generation. The density-dependent bioassays were conducted for continuous 6 generations. The population growth rate was calculated as follows: $\mathrm{P}=(\mathrm{N} * \mathrm{~S} * \mathrm{R} * \mathrm{~F} * \mathrm{E}) / \mathrm{N}(\mathrm{P}:$ Population growth rate, $\mathrm{N}$ : Initial nymph number, $\mathrm{S}$ : Nymph survival rate, R: Female ratio, F: Fecundity for per female, E: Egg hatchability) (Yu et al. 2013).

\section{RNA extraction and sequencing}

The insect samples of HFG and LFG reared under low density (10 nymphs per clump) and high density (170 nymphs per clump) at generations F1, F3 and F5 were collected. Total RNA was subsequently extracted from insect samples with TRIzol Reagent according to the manufacturer's instructions. The RNA samples were utilized for tag library preparation using Illumina gene expression sample preparation kit (Illumina, San Diego, CA, USA), following the manufacturer's instructions. The total RNA integrity and quality were assessed using the RNA 6000 Nano LabChip kit and Agilent 2100 Bioanalyzer (Agilent Technologies, Palo Alto, CA, USA). The poly(A)-containing mRNA was purified using magnetic oligo(dT) beads and the Oligotex mRNA kit (Qiagen, Hilden, Germany). The transcriptome sequencing library 
was prepared according to a modified method ( $\mathrm{Su}$ et al. 2012). The mRNA strands were cleaved into short fragments by fragmentation buffer and reverse-transcribed for cDNA synthesis.

Two replicates of each treatment were used for RNA sequencing. The cDNA library ( $\sim 300$ base pairs-long) was sequenced using Illumina HiSeq ${ }^{\mathrm{TM}} 4000$ sequencing platform (Illumina, San Diego, CA, USA). The adapter sequences, empty reads, and low-quality sequences (i.e. reads with a ratio of unknown sequences ' $\mathrm{N}$ ' $>5 \%$ ) were removed to obtain clean reads. All clean reads were mapped to the N. lugens genome (Accession No. GCF_000757685.1) with Hisat2 software (Kim et al. 2015). Read counts for all transcripts were extracted with HTSeq-count (Anders et al. 2015) and then transfer to FPKM (Fragments Per Kilobase Million) with $\mathrm{R}$ software GenomicFeatures (https://git.bioconductor.org/packages/GenomicFeatures).

\section{Temporal analysis}

We generated a FPKM matrix of all transcripts in all samples. Then the samples were divided into four groups: HFG under low density (HFG-LD), HFG under high density (HFG-HD), LFG under low density (LFG-LD), and LFG under high density (HFG-HD). For each group, the temporal expression pattern from F1 to F5 of all genes was calculated with the corresponding FPKM matrix by using the Short Time-series Expression Miner (STEM) software (Ernst and Bar-Joseph 2006). The cluster number was set to 12 for each analysis.

\section{Identification and annotation of candidate co-expression gene modules}

Genes with FPKM lower than 0.3 in a sample were considered as "too lowly expressed" (Kang et al. 2013; Bai et al. 2015). We filtered the FPKM matrix by removing the transcripts that showed too low expression in more than half of the tested samples. The filtered matrix was then used for inferring the co-expression gene network modules by using weighted gene co-expression network analysis (WGCNA) in R (Langfelder and Horvath 2008). The parameters were set as "power $\beta=6$, min module size $=50$, ME miss thread $=0.25$ ".

The candidate co-expression gene modules were selected according to the temporally analyzed gene list. The genes in candidate modules were annotated to the KEGG pathway 
database, and the pathway enrichment analysis was performed based on the Fisher's exact test with Benjamini and Hochberg (BH) adjustment by using the KEGG annotation of all genes in the $\mathrm{BPH}$ as background.

\section{Differential expression analysis and quantitative real-time PCR validation}

The read counts generated by HTseq-count were normalized using R package DESeq2 (Love et al. 2014). Then the differentially expressed genes (DEGs) between pairwise comparisons were estimated by DESeq2 according to the threshold of $\mid \log 2$ ratio $\mid>1$ and adjusted $P$-value $<0.05$ (BH adjustment).

To support the analysis, twenty DEGs were randomly selected for measurement of expression. Total RNA $(1 \mu \mathrm{g})$ reverse-transcribed into first-strand cDNA using a PrimeScript ${ }^{\mathrm{TM}}$ RT reagent kit (Takara Bio, Inc. Otsu, Shiga, Japan). qPCR was performed using a $10-\mu \mathrm{L}$ reaction containing $1 \mu \mathrm{L}$ cDNA, $0.3 \mu \mathrm{L}$ each of $10 \mu \mathrm{mol} \cdot \mathrm{L}^{-1}$ forward and reverse primers, and $5 \mu \mathrm{L}$ SYBR ${ }^{\circledR}$ FAST Universal qPCR mix (KAPA Biosystems, Woburn, MA, USA) and LightCycler 480 system (Roche Diagnostics GmbH, Mannheim, Germany), with the following amplification conditions: $5 \mathrm{~min}$ at $95^{\circ} \mathrm{C}$, followed by 45 cycles at $95^{\circ} \mathrm{C}$ for $10 \mathrm{~s}$, at $60^{\circ} \mathrm{C}$ for $20 \mathrm{~s}$, and at $72^{\circ} \mathrm{C}$ for $20 \mathrm{~s}$. The qPCR experiments were performed for each sample using three biological and three technical replicates. The expression levels of selected genes were normalized to the expression levels of $N$. lugens $\beta$-actin (Chen et al. 2013). The differential gene expression was calculated using the $2^{-\Delta \Delta \mathrm{Ct}}$ method (Livak and Schmittgen, 2001).

\section{RNA interference of Nlpale}

Gene Nlpale encoding tyrosine hydroxylase [ $\mathrm{TH}$; the rate-limiting enzyme in dopamine production metabolic pathway] was selected as the key regulatory factor, and its function was validated by RNA interference (RNAi). For double-stranded RNA (dsRNA) synthesis, a 466-bp fragment (Nlpale) were amplified by PCR using Nlpale cDNAs. All primers contained the T7 promoter sequence at each end (Table S1). The dsRNA of Aequorea victoria green fluorescent protein (GFP, Accession No. ACY56286) was used as a control (Qiu et al. 2016; Pang et al. 2017). The T7 RiboMAX Express RNAi System (Promega, USA) was used to 
synthesize dsRNA according to the manufacturer's instructions. The concentrations of dsRNA were quantified spectrophotometrically with a NanoDrop 2000 instrument (Thermo Fisher Scientific, Waltham, MA, USA). Finally, the quality and size of the dsRNA were further verified via $1 \%$ agarose gel electrophoresis.

The 1-day-old female adults of HFG and LFG were used for RNAi. The dsRNA injection experiment was mainly conducted as previously described (Chen et al. 2013). Briefly, approximately $250 \mathrm{ng}$ dsRNA was injected into the mesothorax of the individuals. Three females were randomly collected to test the RNAi efficiency by quantitative real-time PCR (qRT-PCR) at $24 \mathrm{~h}$ after injection. Then the injected females were mated with male adults at the ratio $1: 1$, and were released to potted rice according to the densities of 10,90 , and 170 individuals respectively. The method for qRT-PCR and fecundity bioassay of the treated insects was as described above. The total number of offsprings from each treatment was counted.

\section{Manipulation of dopamine in the BPH}

The Insect Dopamine elisa kit (Boshen Biotechnology, Jiangsu, China) was applied to detect the dopamine content in the BPH following the manufacturer's instruction. In brief, every five 1-day-old female adults was used as one repeat and six repeats was conducted for each treatment. The homogenate, standard substance and horse radish peroxidase (HRP) labeled antibody of dopamine were successively added to the micropores that are precoated with the dopamine antibody, and were incubated in $37^{\circ} \mathrm{C}$. Then the incubation was washed, and the substrate 3', 3', 5', 5', -tetramethyl benzidine (TMB) is used for color rendering. The absorbance (OD value) was measured at the wavelength of $450 \mathrm{~nm}$ to reflect the dopamine content in the samples.

Dopamine hydrochloride (Sigma-Aldrich), a dopamine activator, and chlorpromazine (CPZ), which was a dopamine receptor antagonist, were dissolved in ringer's solution. The pharmacological injection experiment was mainly conducted as previously described (Ma et al. 2011; Chen et al. 2013). The injection metering of dopamine hydrochloride is $100 \mathrm{nl}$ of $80 \mu \mathrm{g} / \mu \mathrm{l}$ while $\mathrm{CPZ}$ is $100 \mathrm{nl}$ of $20 \mu \mathrm{g} / \mu \mathrm{l}$ solution. They were injected into the mesothorax of the BPH. Ringer's solution was used as the control. The qRT-PCR and fecundity bioassay 
after injection was the same as described above.

\section{Detection of the hormone 20 - hydroxyecdysone content}

The content of hormone 20 - hydroxyecdysone (20E) in the BPH was detected with the Insect Ecdysone ELISA Assay kit (Boshen Biotechnology) according to the manufacturer's instruction. Briefly, every five 1-day-old female adults was used as one repeat and six repeats was conducted for each treatment. The homogenate, standard substance and horse radish peroxidase (HRP) labeled antibody of ecdysone were successively added to the micropores that are precoated with the ecdysone antibody, and were incubated in $37^{\circ} \mathrm{C}$. Then the incubation was washed, and the substrate $3^{\prime}, 3^{\prime}, 5^{\prime}, 5^{\prime}$, -tetramethyl benzidine (TMB) is used for color rendering. The absorbance (OD value) was measured at the wavelength of 450 $\mathrm{nm}$ to reflect the ecdysone content in the samples.

\section{Statistical analysis}

The impact of density, generation, genotype and their combinations on insect fecundity and population growth rate was analyzed with multi-factor analysis of variance (multi-way ANOVA) and Tukey's test using SPSS 18.0 statistical software. The differences in pairwise comparison on gene expression levels and offspring number of the BPH were analyzed with student's $t$-test using SPSS 18.0. Statistical differences were considered significant at $P<0.05$ or very significant at $P<0.01$. The differences amongst multiple comparisons were tested by

\section{Results}

Population density modulates the fecundity of BPH

The population growth trends and dynamics between HFG and LFG under the densities of 10 , 50, 90, 130 and 170 nymphs were measured for 6 continuous generations. The density, generation, genotype and the combinations of these factors all had significant impacts on the number of offspring per female (Table S2). Both genotypes showed a lower fecundity in a higher individual density (Fig. 1A). Under the densities of 90, 130 and 170 nymphs, the 
offspring number of HFG showed a decreased trend across generations, while the tendencies under low densities (10 and 50 nymphs) were opposite. In contrast, the LFG showed higher fecundity as the generation increasing in all tested densities except for the highest one (170 nymphs). There was no significant difference between most adjacent generations in LFG under the density of 170 nymphs.

The differential response to the population density between these two genotypes of BPH was also seen from statistics of the population growth rate (Table S2). The population growth rate of HFG presented a significantly rising trend under low population densities (10 and 50 nymphs) and a significantly decreasing trend under high population densities (90, 130 and 170 nymphs) (Fig. 1B). The LFG demonstrated similar change in the population growth rate under low densities, however, the changing of the population growth rate was not obvious for LFG under high densities (Fig. 1B). These findings suggested that BPH populations with different fecundity-determined genotypes were quite different in their strategies of population regulation to density changes.

\section{Temporal expression trends revealed by RNA-seq}

RNA-seq experiments were conducted to explore the key factors responsible for different response to density changes between HFP and LFP. Insects reared on the densities of 10 (low density, LD) and 170 (high density, HD) nymphs were selected, and samples were collected at F1, F3 and F5. The RNA-seq produced an average 33,320,239 clean paired-end reads per sample with Q30 value higher than 92\% (Table S3). The average mapping rate of all samples to the reference genome of the BPH was $54.43 \%$ (Table S3), and a FPKM matrix of 24,306 analysis.

We applied temporal analysis with the filtered FPKM matrix to each treatment (HFG-LD, HFG-HD, LFG-LD, and LFG-HD) independently. According to the fecundity phenotype, the key factors in both HFG and LFG should show a linear correlation to the fecundity under low density, thus the transcripts showing continuous increasing or decreasing trend along with generations in group HFG-LD and LFG-LD were selected (Fig. 2A). For both genotypes 
under high density, the key factors should show differential expression patterns to those under low density. Additionally, the expression patterns of key factors between HFG and LFG under high density should also be inconsistent. By using these considerations as filter parameters, we finally identified 31 candidate genes (Fig. 2B). The expression levels of these genes demonstrated significantly high correlation between HFG-LD and LFG-LD, while most of them only show low correlation in the other comparisons (HFG-LD to HFG-HD, LFG-LD to LFG-HD, and HFG-HD to LFG-HD) (Fig. 2C).

\section{Identification of the key regulatory factor for density-dependent progenitive phenotypes}

To further determine the key factors for density-dependent progenitive phenotypes, we conducted weighted gene co-expression network analysis (WGCNA). All the filtered transcripts were used for this analysis. The analysis resulted in 16 distinct gene modules (Fig. 3A, Table S5). The 31 candidate genes were distributed in eight of the modules. Among them, the turquoise and darkred modules accounted for most of the candidate genes $(21 / 31$, Table S6). The KEGG pathway enrichment of the genes in these two modules was analyzed. The genes in turquoise module were significantly enriched in a total of 69 pathways, while the number of enriched pathways for the genes in darkred module was 25 (Table S7). Remarkably, four pathways were identified to be enriched for both modules, which included Endocrine and other factor-regulated calcium reabsorption, Axon regeneration, Dopaminergic synapse, and Regulation of actin cytoskeleton (Fig. 3B). This finding suggested that these pathways might play important roles in regulation of fecundity between different population densities.

According to the phenotypic difference, the key factors should show significantly differential expression between HFG-HD and HFG-LD at F5. Thus, a differential expression analysis was conducted on these two datasets. The analysis identified a total of 464 DEGs in HFG-HD compared to HFG-LD, including 311 up-regulated and 153 down-regulated genes (Fig.4A, Table S8). Among the DEGs, only six were involved in the above four pathways. And importantly, only one of the 6 DEGs belonged to the candidate transcripts obtained from the temporal analysis. This candidate gene, LOC111049383 (Nlpale), encodes tyrosine hydroxylase that is the key rate-limiting enzyme for dopamine synthesis in organisms (Morgan et al. 1996; Ma et al. 2011) (Fig. 4B). The decreased expression trend of gene Nlpale 
in low population density was irrelevant to the fecundity genotypes of BPH (Fig. 4B). However, the expression level of Nlpale was continuously elevated in HFG under high population density with the generations increasing, but similar trend was not seen in LFG under the same treatment. Overall, the expression changes of pale were negatively correlated to the phenotypic changes of fecundity in both genotypes of BPH.

\section{The modulation of gene Nlpale and dopamine in the progenitive plasticity of BPH}

The insects of HFG and LFG under low population fecundity (10 nymphs) were used to determine the basic expression level of gene Nlpale and content of dopamine in different genotypes of BPH. Based on the qRT-PCR analysis, the mRNA level of Nlpale was much higher in LFG than that in HFG (Fig. 5A). Accordingly, the LFG showed higher content of dopamine than the HFG (Fig. 5B). These results were corresponding to the transcriptomic analysis that the expression of gene Nlpale and the fecundity of BPH were negative correlation. This negative regulatory relationship was further confirmed by RNAi of Nlpale. The expression of Nlpale in insects of both genotypes was significantly decreased from 24 to $72 \mathrm{~h}$ after injection of dsRNA, compared with the GFP control (Fig. 5C). Interestingly, the expression of $\mathrm{NlVg}$, an important molecular marker for insect fecundity, were significantly increased in insects of both genotypes at 48 and $72 \mathrm{~h}$ after RNAi of Nlpale (Fig. 5D). Correspondingly, the offspring number of HFG and LFG was significantly elevated after RNAi of Nlpale (Fig. 5E). In addition, when the female adults were supplied with extra dopamine hydrochloride by micro-injection, their offspring number was significantly declined. And the injection of $\mathrm{CPZ}$, a dopamine inhibitor, resulted in the increasing of offspring number in corresponding female adults (Fig. 5F). The negative correlation between dopamine content and fecundity had no difference between insects of HFG and LFG, indicating the intrinsic regulatory role of dopamine biosynthesis in the fecundity of BPH.

We further investigated that whether Nlpale and dopamine were the key factors to determine the difference in response to population density changes between HFG and LFG insects. A significant correlation between the content of dopamine and the fecundity were observed on the insects from both genotypes under different population densities across 6 generations $\left(\mathrm{R}=-0.88\right.$ and $P$-value $=1.52 \times 10^{-6}$ for $\mathrm{HFG}$, and $\mathrm{R}=-0.90$ and $P$-value $=3.45 \times 10^{-7}$ 
for LFG, Fig. S1). Then the fecundity of Nlpale RNAi-treated insects of both genotypes was compared to those of GFP control. In the control traits, the average fecundity of both genotypes was significantly decreased as the population density increasing (Fig. 6A). When the Nlpale was knockdown, the density-dependent change of fecundity in LFG were almost disappeared (Fig. 6B). However, the absence of density effect only found in the HFG under high population density (130 and 170 nymphs). We subsequently modulated the content of dopamine in the insects of HFG and LFG. Interestingly, the injection of dopamine hydrochloride and CPZ all eliminated the density effect on fecundity of LFG, and similar result was only observed on high population density-treated samples of the HFG (Fig.6C and 6D). These results suggested that the disruption of dopamine biosynthesis has great impact on the density-dependent progenitive plasticity of BPH.

Previous studies have showed that the dopamine can regulate the biosynthesis of other insect hormones (Gruntenko et al. 2005a; 2005b; Rauschenbach et al. 2007). Thus, the relationship between the hormone $20 \mathrm{E}$ and dopamine in this density-dependent experiment was assessed. Accordingly, the content of $20 \mathrm{E}$ was negatively correlated to the dopamine content but positively correlated to the fecundity in BPH samples under different densities across different generations (Fig. S1). Additionally, the RNAi of gene Nlpale lead to the increase of $20 \mathrm{E}$ in the insect of both genotypes (Fig. S2), indicating the intrinsic regulation relationship between dopamine and $20 \mathrm{E}$ in this species.

\section{Discussion}

In the present study, we validated the progenitive plasticity in the BPH populations with two different fecundity-related genotypes. Under the continuous condition of low density, the insect population continuously expanded by the elevation of individual fecundity, and this elevation was independent of the genotypes. When under the continuous high density, the HFG insect continuously reduced its individual fecundity as well as the population growth rate, but this decreasing trend was not observed on the LFG (Fig. 1).

Our findings can be largely explained by the traditional theory of density-dependent population regulation. Nicholson (1933) proposed that the population could adjust density according to its own natural and environmental conditions. All species would balance their 
population density with the resources which they need to live. Accordingly, a population density higher than the balance can be restricted by a series of morphological, physiological, behavioral, and genetic factors to prevent the population from infinite growing (Chitty 1960). In turn, the factors suppressing population growth will be weakened if the population density is lower than the balance (Murdoch 1994; Turchin 1999). The changes in the population growth rate of treatments LFG-LD, HFG-LD and HFG-HD were basically conformed with this hypothesis. For the treatment of LFG under high density, the fecundity showed increased trends but the population growth rate was overall stable across different generations. One possibility was that there exist some thresholds for population balance under different densities in this species. For high density, the threshold was to the advantage of LFG. Thus, the LFG under these densities could rapidly reach the state of balance, as was observed from the stabilized population growth rates.

RNA-seq and a series of bioinformatic analysis were utilized to unveil the determinant for the phenotypic difference between HFG and LFG under high population density. The analyzed results centralized at four pathways (Fig. 3B). Interestingly, all these pathways were closely related to the neural system. The Regulation of actin cytoskeleton is an essential process during axonogenesis, because that the neuroblast growth must undergo an engorgement that involves depolymerization of actin (Bradke and Dotti 1999) followed by the penetration of the microtubules into the central and peripheral domains (Kunda et al. 2001). Endocrine and other factor-regulated calcium reabsorption is a pathway associated with calcium regulation in organism, while calcium ion plays an important role in the activity of neural synaptotagmin ( $\mathrm{Li}$ et al. 1995; Tucker et al. 2004). Importantly, the pathways of Axon regeneration and Dopaminergic synapse were exactly the components of the neural system (Neve et al. 2004; Hammarlund and Jin 2014).

Our subsequent research found that the dopamine was the key factor in modulating the fecundity of BPH. Interestingly, it seems that the fecundity was negative correlated to its dopamine content in the BPH (Fig. 4 and Fig. 5). Dopamine is a catecholamine neurotransmitter that is synthesized in both neuronal and non-neuronal tissues. It plays an important role in insect development and is known to be involved in insect's stress responses (Neckameyer 1996; Neckameyer and Weinstein 2005). Dopamine can act as a 
neuromodulator to stimulate behavior like arousal, reproductive and locomotor activity (Neckameyer et al. 2000; Pendleton et al. 2002; Pfeiffenberger and Allada 2012). Environmental stress, such as heat, parasite infection can affect dopaminergic signaling pathways in insects, then in turn, insects can benefit from dopamine to adapt to external environment by modulating ontogenesis and development (Hirashima et al. 2000; Gruntenko et al. 2000, 2004; Lavista-Llanos et al. 2014). Actually, it has been previously reported that dopamine can also regulate insect reproduction by modulating female sexual receptivity, oogenesis, and oviposition (Neckameyer 1998; Boulay 2001). Meanwhile, the change in dopamine content can cause the changes in other hormones like $20 \mathrm{E}$ and $\mathrm{JH}$, indicating its potential regulative role to these hormones (Gruntenko et al. 2005a, 2005b; Rauschenbach et al. 2007). Our data also suggested that the $20 \mathrm{E}$ content was negatively regulated by the dopamine (Fig. S2). In BPH, the 20E content in female adults is significant associated with their progenitive capacity (Yu et al. 2014; Zhou et al. 2020). Thus, the regulation of dopamine biosynthesis on the fecundity of BPH may go through the 20E signal pathway. Further research will be conducted to investigate this regulative approach.

More importantly, our study showed that dopamine exactly contributed to the density-dependent progenitive plasticity of BPH. Both RNAi of the tyrosine hydroxylase coding gene (Nlpale) and modulating of the dopamine content in insects significantly disturbed the density effect on the fecundity of BPH (Fig. 6). In Locusta migratoria, the transitions between solitary and gregarious phases in response to population density changes are closely related to dopamine biosynthesis (Ma et al. 2011; Zhang et al. 2020). Here, we assumed that the different population densities would release different signals to the brain of insects, which differentially regulate the pathway of dopamine synthesis and thus result in the different changes in female fecundity. The trend of phenotypic change across generations is finally determined by the population genotype that is associated to the distance to population balance under a specific density.

In summary, we demonstrated that the dopamine biosynthesis is the key regulatory factor for density-dependent progenitive plasticity in the $\mathrm{BPH}$. The findings in this study provide insights into the interaction of genotypes and environmental factors in regulating insect population dynamics, and will facilitate the understanding of the mechanism behind the 
population regulation.

\section{Acknowledgements}

This work was supported by the National Natural Science Foundation of China (31672021 and 31730073), and the Young Innovative Talents Project of Ordinary University of Guangdong Province, China (KA2001961).

\section{Data Accessibility}

All sequencing data were deposited to the NCBI Sequence Read Archive (SRA; http://www.ncbi.nlm.nih.gov/sra/) under the BioProject PRJNA690237.

\section{Author Contributions}

KL, WZ and RP conceived and designed the study. KL, RP, WC and KK conduct the experiments. KL and RP designed the RNA-seq analysis pipeline, and performed the data analysis. LYY, LY, and JL contributed to materials. KL, WZ and RP wrote the manuscript.

\section{References}

Berg A, Lindberg T, Kallebrink KG (1992) Hatching success of lapwings on farmland

Anders S, Pyl PT, Huber W (2015) HTSeq-a Python framework to work with high-throughput sequencing data.

Bioinformatics

31:166-169. https://doi.org/10.1093/bioinformatics/btu638

Arcese P, Smith JNM (1988) Effects of population-density and supplemental food on reproduction in song sparrows. J Anim Ecol 57:119-136. https://doi.org/10.2307/4768

Bai Y, Dougherty L, Cheng LL, Zhong GY, Xu KN (2015) Uncovering co-expression gene network modules regulating fruit acidity in diverse apples. BMC Genomics 16:612. https://doi.org/10.1186/s12864-015-1816-6

Bainton RJ, Tsai LT, Singh CM, Moore MS, Neckameyer WS, Heberlein U (2000) Dopamine modulates acute responses to cocaine, nicotine and ethanol in Drosophila. Curr Biol 10:187-194. https://doi.org/10.1016/s0960-9822(00)00336-5 differences between habitats and colonies of different sizes. J Anim Ecol 61:469-476. 
https://doi.org/10.2307/5337

Boulay R, Hooper-Bui LM, Woodring J (2001) Oviposition and oogenesis in virgin fire ant females Solenopsis invicta are associated with a high level of dopamine in the brain. Physiol Entomol 26:294-299. https://doi.org/10.1046/j.0307-6962.2001.00250.x

Bradke F, Dotti CG (1999) The role of local actin instability in axon formation. Science 283:1931-1934. https://doi.org/10.1126/science.283.5409.1931

Chen J, Liang Z, Liang Y, Pang R, Zhang W (2013) Conserved microRNAs miR-8-5p and miR-2a-3p modulate chitin biosynthesis in response to 20-hydroxyecdysone signaling in the brown planthopper, Nilaparvata lugens. Insect Biochem Molec 43:839-848. https://doi.org/

Chitty D (1960) Population processes in the vole and their relevance to general theory. Can J Zool 38: 99-113. https://doi.org/10.1139/z60-011

Edward DA, Poissant J, Wilson AJ, Chapman T (2014) Sexual conflict and interacting phenotypes: a quantitative genetic analysis of fecundity and copula duration in Drosophila Melanogaster. Evolution, 68:1651-1660. https://doi.org/10.1111/evo.12376

Ernst J, Bar-Joseph Z (2006) STEM: a tool for the analysis of short time series gene expression data. BMC Bioinformatics 7:191. https://doi.org/10.1186/1471-2105-7-191

Ge LQ, Cheng Y, Wu JC, Jahn GC (2011) Proteomic analysis of insecticide triazophos-induced mating-responsive proteins of Nilaparvata lugens Stål (Hemiptera: Delphacidae). J Proteome Res 10:4597-4612. https://doi.org/10.1021/pr200414g

Geister TL, Lorenz MW, Meyering-Vos M, Hoffmann KH, Fischer K (2008) Effects of temperature on reproductive output, egg provisioning, juvenile hormone and vitellogenin titres in the butterfly Bicyclus anynana. J Insect Physiol 54:1253-1260. https://doi.org/10.1016/j.jinsphys.2008.06.002

Grimaldi D, Engel MS (2005) Evolution of the insects. Cambridge University Press, Cambridge, New York

Gruntenko NE, Karpova EK, Adonyeva NV, Chentsova NA, Faddeeva NV, Alekseev AA, Rauschenbach IY (2005a) Juvenile hormone, 20-hydroxyecdysone and dopamine interaction in Drosophila virilis reproduction under normal and nutritional stress conditions. J Insect Physiol 51:417-425. https://doi.org/10.1016/j.jinsphys.2005.01.007 
Gruntenko NE, Karpova EK, Alekseev AA, Chentsova NA, Saprykina ZV, Bownes M, Rauschenbach IY (2005b) Effects of dopamine on juvenile hormone metabolism and fitness in Drosophila virilis. J Insect Physiol 51:959-968. https://doi.org/10.1016/j.jinsphys.2005.04.010

Gruntenko NE, Khlebodarova TM, Vasenkova IA, Sukhanova MJ, Wilson TG, Rauschenbach IY (2000) Stress-reactivity of a Drosophila melanogaster strain with impaired juvenile hormone action. J Insect Physiol 46:451-456. https://doi.org/10.1016/s0022-1910(99)00131-6

Gruntenko NE, Raushenbakh IY (2004) Adaptive value of genes controlling the level of biogenic amines in Drosophila. Genetika 40:869-876. https://doi.org/10.1023/B:RUGE.0000036517.62459.8d

Hammarlund M, Jin Y (2014) Axon regeneration in C. elegans. Curr Opin Neurobiol 27:199-207. https://doi.org/10.1016/j.conb.2014.04.001

Hanski I, Saccheri I (2006) Molecular-level variation affects population growth in a butterfly metapopulation. PloS Biology 4:719-726. https://doi.org/10.1371/journal.pbio.0040129

Hari NS, Jindal J, Malhi NS, Khosa JK (2008) Effect of adult nutrition and insect density on the performance of spotted stem borer, Chilo partellus in laboratory cultures. J Pest Sci 81:23-27. https://doi.org/10.1007/s10340-007-0180-y

Hassell MP (1975) Density-dependence in single-species populations. J Anim Ecol 44:283-295. https://doi.org/10.2307/3863

Hirashima A, Sukhanova M, Rauschenbach I (2000) Biogenic amines in Drosophila virilis under stress conditions. Biosci Biotech Bioch 64:2625-2630. https://doi.org/ 10808867

Horgan FG, Naik BS, Iswanto EH, Almazan MLP, Ramal AF, Bernal CC (2016) Responses by the brown planthopper, Nilaparvata lugens, to conspecific density on resistant and susceptible rice varieties. Entomol Exp Appl 158:284-294. https://doi.org/10.1111/eea.12400

Kang CY, Darwish O, Geretz A, Shahan R, Alkharouf N, Liu ZC (2013) Genome-scale transcriptomic insights into early-stage fruit development in woodland strawberry Fragaria vesca. Plant Cell 25:1960-1978. https://doi.org/ 10.1105/tpc.113.111732

Kim D, Landmead B, Salzberg SL (2015) HISAT: a fast spliced aligner with low memory 
requirements. Nat Methods 12:357-360. https://doi.org/10.1038/nmeth.3317

Kunda P, Paglini G, Quiroga S, Kosik K, Caceres A (2001) Evidence for the involvement of

in

axon

formation.

NEUROSCI

$21: 2361-2372$ https://doi.org/10.1523/jneurosci.21-07-02361.2001

Langfelder P, Horvath S (2008) WGCNA: an R package for weighted correlation network analysis. BMC Bioinformatics 9:1-32. https://doi.org/10.1186/1471-2105-9-559

Lavista-Llanos S, Svatos A, Kai M, Thomas R, Serge B, Stensmyr MC, Hansson BS (2014) Dopamine drives Drosophila sechellia adaptation to its toxic host. Elife 3:e03785. https://doi.org/10.7554/eLife.03785

Li C, Ullrich B, Zhang JZ, Anderson RGW, Brose N, Südhof TC (1995) $\mathrm{Ca}^{2+}$-dependent and -independent activities of neural and non-neural synaptotagmins. Nature 375:594-599. https://doi.org/10.1038/375594a0

Liu K, Chen Z, Su Q, Yue L, Chen WW, Zhang WQ (2020) Comparative analysis of the ecological fitness and transcriptome between two genotypes of the brown planthopper $\begin{array}{lllll}\text { Nilaparvata } \quad \text { lugens. } & \mathrm{J} & \text { Integr } & \text { Agr } & \text { 19:1501-1511. }\end{array}$ https://doi.org/10.1016/S2095-3119(19)62768-1

Livak KJ, Schmittgen TD (2001) Analysis of relative gene expression data using real-time quantitative PCR and the $2^{-\triangle \Delta C T}$ method. Methods 25:402-408. https://doi.org/10.1006/meth.2001

Love MI, Huber W, Anders S (2014) Moderated estimation of fold change and dispersion for RNA-seq data with DESeq2. Genome Biol 15:31-46. https://doi.org/10.1186/s13059-014-0550-8

Ma ZY, Guo W, Guo XJ, Wang XH, Kang L (2011) Modulation of behavioral phase changes of the migratory locust by the catecholamine metabolic pathway. P Natl Acad Sci USA 108:3882-3887. https://doi.org/10.1073/pnas.1015098108

Morgan WW, Walter CA, Windle JJ, Sharp ZD (1996) $3.6 \mathrm{~kb}$ of the 5' flanking DNA activates the mouse tyrosine hydroxylase gene promoter without catecholaminergic-specific expression. https://doi.org/10.1046/j.1471-4159.1996.66010020.x

Mori K, Nakasuji F (1991) Effects of day length and density on development and wing form 

of the small brown planthopper, Laodelphax striatellus (Hemiptera: Delphacidae). Appl Entomol Zool 26:557-561. https://doi.org/10.1303/aez.26.557

Murdoch WW (1994) Population regulation in theory and practice. Ecology 75:271-287. https://doi.org/10.2307/1939533

Neckameyer WS (1996) Multiple roles for dopamine in Drosophila development. Dev Biol 176:209-219. https://doi.org/10.1006/dbio.1996.0128

Neckameyer WS (1998) Dopamine modulates female sexual receptivity in Drosophila melanogaster. J Neurogenet 12:101-114. https://doi.org/10.3109/01677069809167259

Neckameyer WS, Weinstein JS (2005) Stress affects dopaminergic signaling pathways in $\begin{array}{llll}\text { Drosophila } & \text { melanogaster. } & \text { Stress }\end{array}$ https://doi.org/10.1080/10253890500147381

Neve KA, Seamans JK, Trantham-Davidson H (2004) Dopamine receptor signaling. J Recept Sig Transd 24:165-205. https://doi.org/10.1081/RRS-200029981

Nicholson AJ (1933) The balance of animal populations. J Anim Ecol 2:132-178. https://doi.org/10.2307/954

Pacala SW, Hassell MP (1991) The persistence of host-parasitoid associations in patchy environments. II. evaluation of field data. Am Nat 138:584-605. https://doi.org/ $10.2307 / 2462455$

Pang R, Qiu JQ, Li TC, Yang P, Yue L, Pan XY, Zhang WQ (2017) The regulation of lipid metabolism by a hypothetical P-loop NTPase and its impact on fecundity of the brown planthopper.

BBA-Gen

Subjects 1861:1750-1758. https://doi.org/10.1016/j.bbagen.2017.03.011

Pendleton RG, Rasheed A, Sardina T, Tully T, Hillman R (2002) Effects of tyrosine hydroxylase mutants on locomotor activity in Drosophila: a study in functional genomics. Behav Genet 32:89-94. https://doi.org/10.1023/A:1015279221600

Pfeiffenberger C, Allada R (2012) Cul3 and the BTB adaptor insomniac are key regulators of sleep homeostasis and a dopamine arousal pathway in Drosophila. PLoS Genet 8:e1003003. https://doi.org/10.1371/journal.pgen.1003003

Qiu J, He Y, Zhang J, Kang K, Li T, Zhang WQ (2016) Discovery and functional identification of fecundity-related genes in the brown planthopper by large-scale RNA 
interference. Insect Mol Biol 25:724-733. https://doi.org/10.1111/imb.12257

Rauschenbach IY, Chentsova NA, Alekseev AA, Gruntenko NE, Adonyeva NV, Karpova EK, Bowens M (2007) Dopamine and octopamine regulate 20-hydroxyecdysone level in vivo in Drosophila. Arch Insect Biochem 65:95-102. https://doi.org/10.1002/arch.20183

Rosenheim JA (1998) Higher-order predators and the regulation of insect herbivore $\begin{array}{lllll}\text { populations. } & \text { Annu } & \text { Rev } & \text { Entomol } & \text { 421-447. }\end{array}$ https://doi.org/10.1146/annurev.ento.43.1.421

Silva RM, Santos LV, Caiado MS, Hastenreiter SN (2020) The influence of larval density on triacylglycerol content in Aedes aegypti (Linnaeus) (Diptera: Culicidae). Arch Insect Biochem e21757. https://doi.org/10.1002/arch.21757

Stiling P (1988) Density-dependent processes and key factors in insect populations. J Anim Ecol 57:581-593. https://doi.org/10.2307/4926

Sun ZX, Zhai YF, Zhang JQ, Kang K, Cai JH, Fu YG, Zhang WQ (2015) The genetic basis of population fecundity prediction across multiple field populations of Nilaparvata lugens. Mol Ecol 24:771-784. https://doi.org/10.1111/mec.13069

Tucker WC, Weber T, Chapman ER (2004) Reconstitution of $\mathrm{Ca}^{2+}$-regulated membrane fusion by synaptotagmin and SNAREs. Science 304:435-438. https://doi.org/10.1126/science.1097196

Turchin P (1999) Population regulation: a synthetic view. Oikos 84:153-159. https://doi.org/10.1353/pbm.2012.0039

Watt WB (1992) Eggs, enzymes, and evolution: natural genetic variants change insect $\begin{array}{lllll}\text { fecundity. } & P & \text { Natl Acad } & \text { Sci }\end{array}$ https://doi.org/10.1073/pnas.89.22.10608

Winkler K, Wackers F, Bukovinszkine-Kiss G, van Lenteren J (2006) Sugar resources are vital for Diadegma semiclausum fecundity under field conditions. Basic Appl Ecol 7:133-140. https://doi.org/10.1016/j.baae.2005.06.001

Yu R, Xu XP, Liang YK, Tian HG, Pan ZQ, Jin SH, Zhang WQ (2014) The insect ecdysone receptor is a good potential target for RNAi-based pest control. Int J Biol Sci 10:1171-1180. https://doi.org/10.7150/ijbs.9598

Yu Y, Xu HX, Zheng XS, Yang YJ, Lu ZX (2013) Effects of drought stress on the ecological 
fitness of brown planthopper, Nilaparvata lugens at high temperature. Acta Phytophy Sin, 40:193-199. https://doi.org/10.13802/j.cnki.zwbhxb.2013.03.001

Zhai YF, Zhang JQ, Sun ZX, Dong XL, He Y, Kang K, Zhang, WQ (2013) Proteomic and transcriptomic analyses of fecundity in the brown planthopper Nilaparvata lugens (Stål). J Proteome Res 12:5199-5212. https://doi.org/10.1021/pr400561c

Zhang X, Xu YN, Chen B, Kang L (2020) Long noncoding RNA PAHAL modulates locust behavioural plasticity through the feedback regulation of dopamine biosynthesis. Plos Genet 16:e1008771. https://doi.org/10.1371/journal.pgen.1008771

Zhou X, Ye YZ, Ogihara MH, Takeshima M, Fujinaga D, Liu CW, Bao YY (2020) Functional analysis of ecdysteroid biosynthetic enzymes of the rice planthopper, Nilaparvata lugens. Insect Biochem Molec 123:103428. https://doi.org/10.1016/j.ibmb.2020.103428

\section{Figure legends}

Fig. 1 The influence of population density on the fecundity (a) and population growth rate (b) of two BPH populations with different fecundity-related genotypes. HFG: High-fecundity genotype BPH; LFG: Low-fecundity genotype BPH. a F1-F6 represent the 1st to 6th generation of nymph density experiment, respectively. The values are presented as mean $\pm \mathrm{SE}$ $(\mathrm{n}=10)$. The values sharing different lowercase letters are significantly different at $P<0.05$ (one-way ANOVA and Duncan's multiple range test).

Fig. 2 Temporal expression trend analysis of the transcriptome data. a Clusters of gene expression trends by the Short Time-series Expression Miner (STEM) software. The gene clusters 1 and 10 of treatments HFG-LD and LFG-LD were selected. b Heatmap representing the expression patterns of 31 candidate genes in each treatment. The trends indicate the expression patterns in treatments HFG-LD and LFG-LD. c The Pearson correlation coefficient of pairwise comparison on the expression levels of candidate genes.

Fig. 3 Identification of co-expression genes related to candidate genes by Weighted gene co-expression network analysis (WGCNA). a Hierarchical cluster tree showing the co-expression modules identified by WGCNA. b The overlapped pathways that are enriched 
for gene modules turquoise and darkred.

Fig. 4 Targeting the key regulatory factors by differential expression analysis. a A volcano plot of the gene expression pattern between HFG-HD and HFG-LD at F5. The black, red and green points represent no difference in expression, up-regulated genes and down-regulated genes (FDR $\leq 0.05$, Benjamini and Hochberg adjustment). b The pathway map of Dopaminergic synapse. The expression patterns of detected genes in this pathway are presented by heatmap.

Fig.5 The role of Nlpale mRNA level and dopamine content in the fecundity of BPH. The Nlpale mRNA levels (a) and dopamine contents (b) in two genotypes insects are presented. The mRNA levels of Nlpale (c) and $\mathrm{NlVg}(\mathbf{d})$ in the two genotypes of BPH were measured at 24, 48 and $72 \mathrm{~h}$ after RNA interference of Nlpale. The insects injected with dsGFP were used as control. e The fecundity of HFG and LFG after injection of Nlpale dsRNA. $\mathbf{f}$ The fecundity of HFG and LFG after injection of dopamine inhibitor chlorpromazine, dopamine hydrochloride (activator), and water control. All data are presented as mean \pm SE. *: $P<0.05$ level; **: $P<0.01$ level (student's $t$-test). The values sharing different letters are significantly different at $P<0.05$ (one-way ANOVA and Duncan's multiple range test).

Fig. 6 The role of dopamine biosynthesis in the density-dependent effects on the fecundity of BPH. The impact of injection of $\operatorname{ds} G F P$ (a), dsNlpale (b), dopamine hydrochloride (c), and chlorpromazine (d) on the fecundity of two genotypes insects under the population densities of 10, 50, 90, 130 and 170 individuals. All data are presented as mean \pm SE. The values sharing different capital letters are significantly different at $P<0.05$ within the HFG, and the values sharing different lowercase letter are significantly different at $P<0.05$ within the LFG (one-way ANOVA and Duncan's multiple range test). 
a

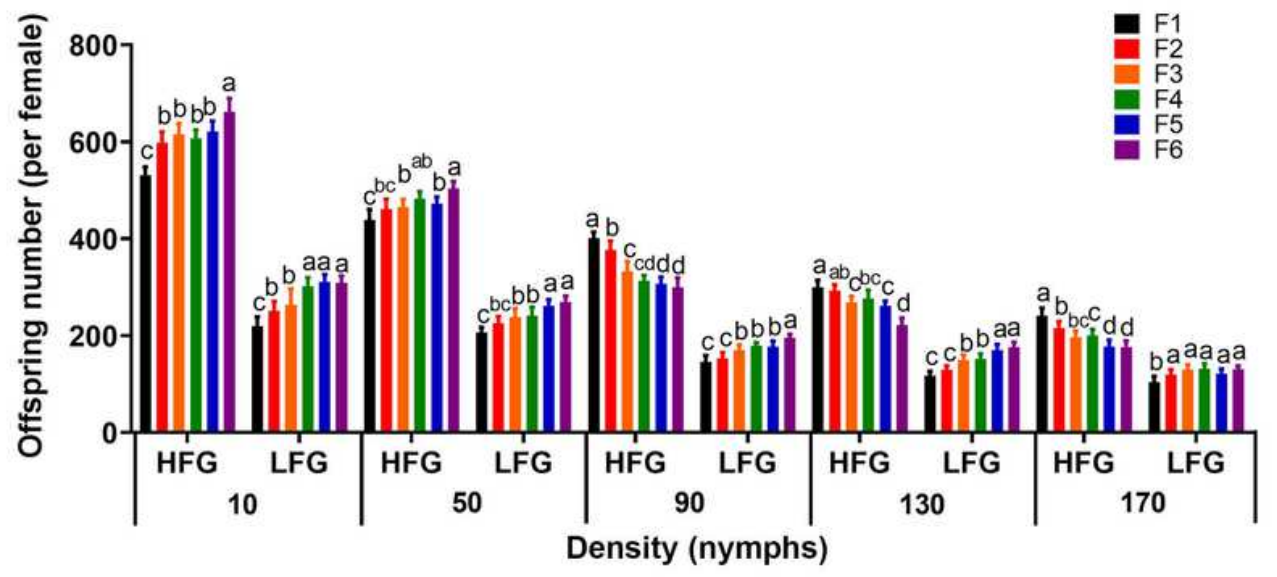

b
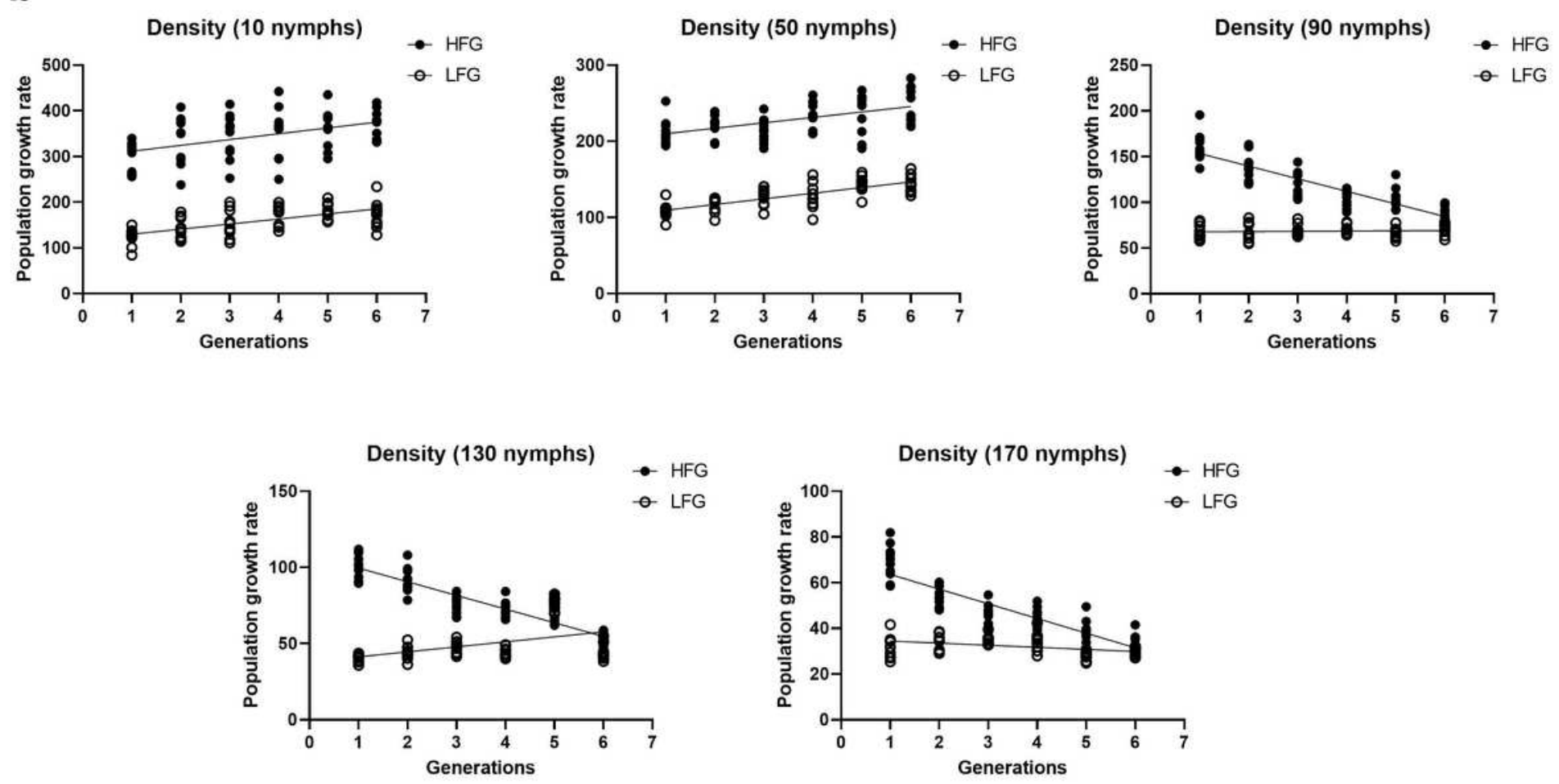

Figure 1

The influence of population density on the fecundity (a) and population growth rate (b) of two BPH populations with different fecundity related genotypes. HFG: High fecundity genotype BPH; LFG: Low fecundity genotype BPH. a F1 F6 represent the 1st to 6th generation of nymph density experiment, respectively. The values are presented as mean $\pm S E(n=10)$. The values sharing different lowercase letters are significantly different at $\mathrm{P}<0.05$ (one way ANOVA and Duncan's multiple range test). 
a
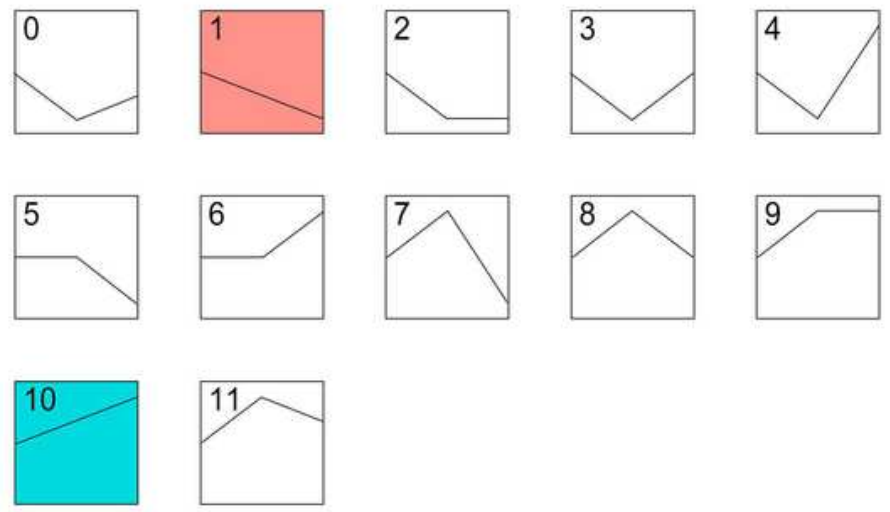

b
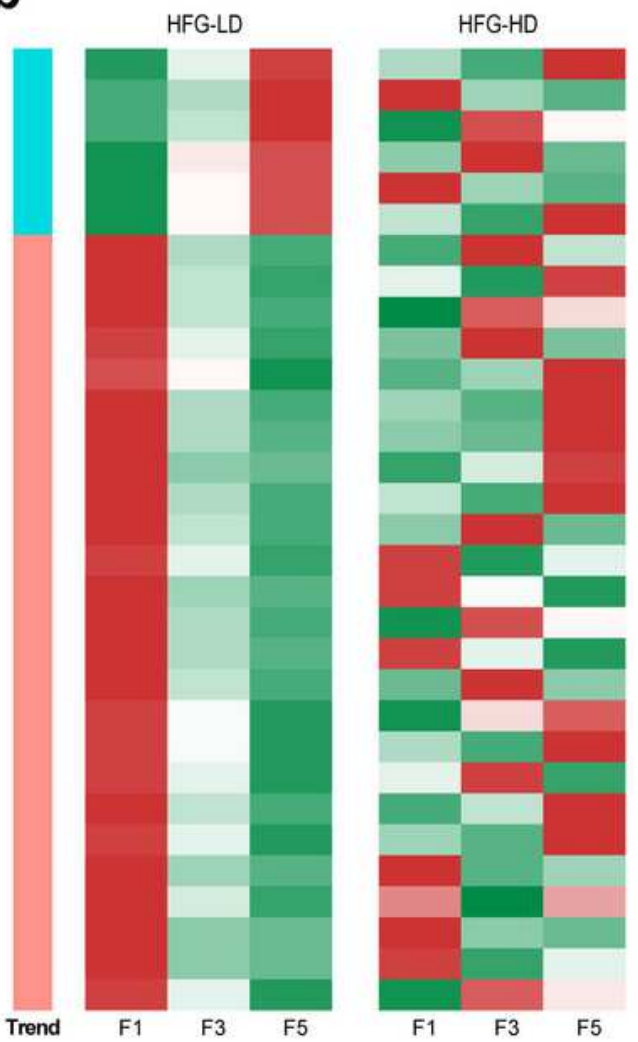

C
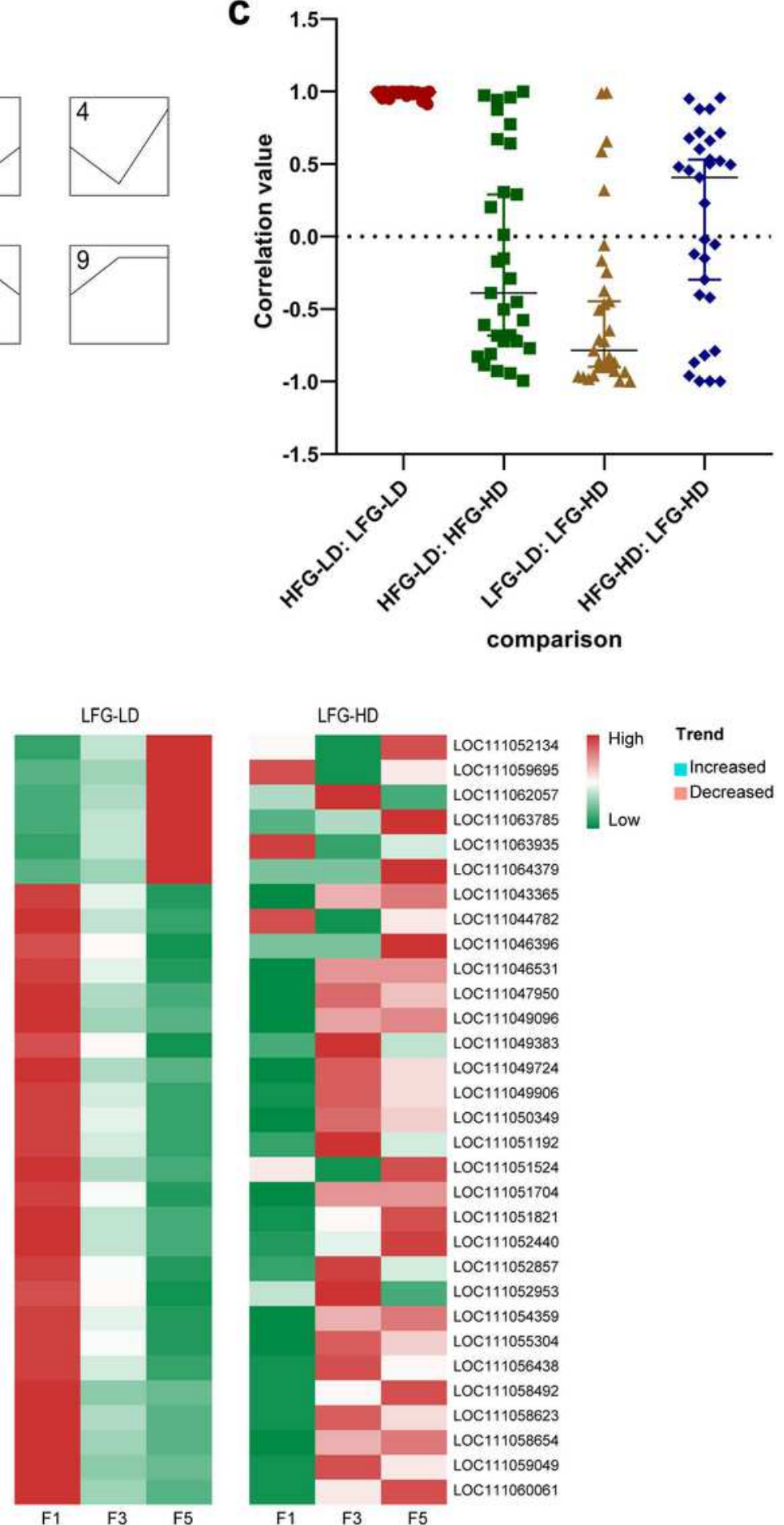

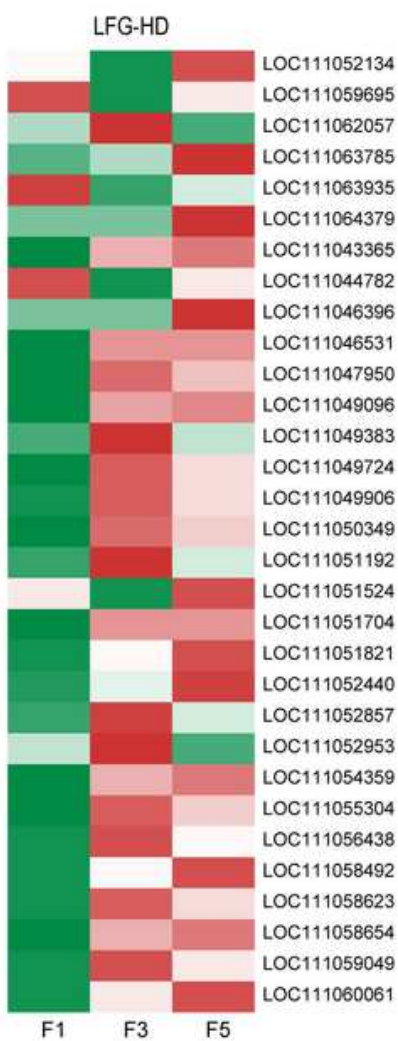

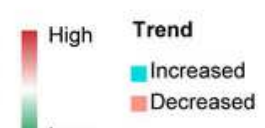

Low

Increased . . 
a

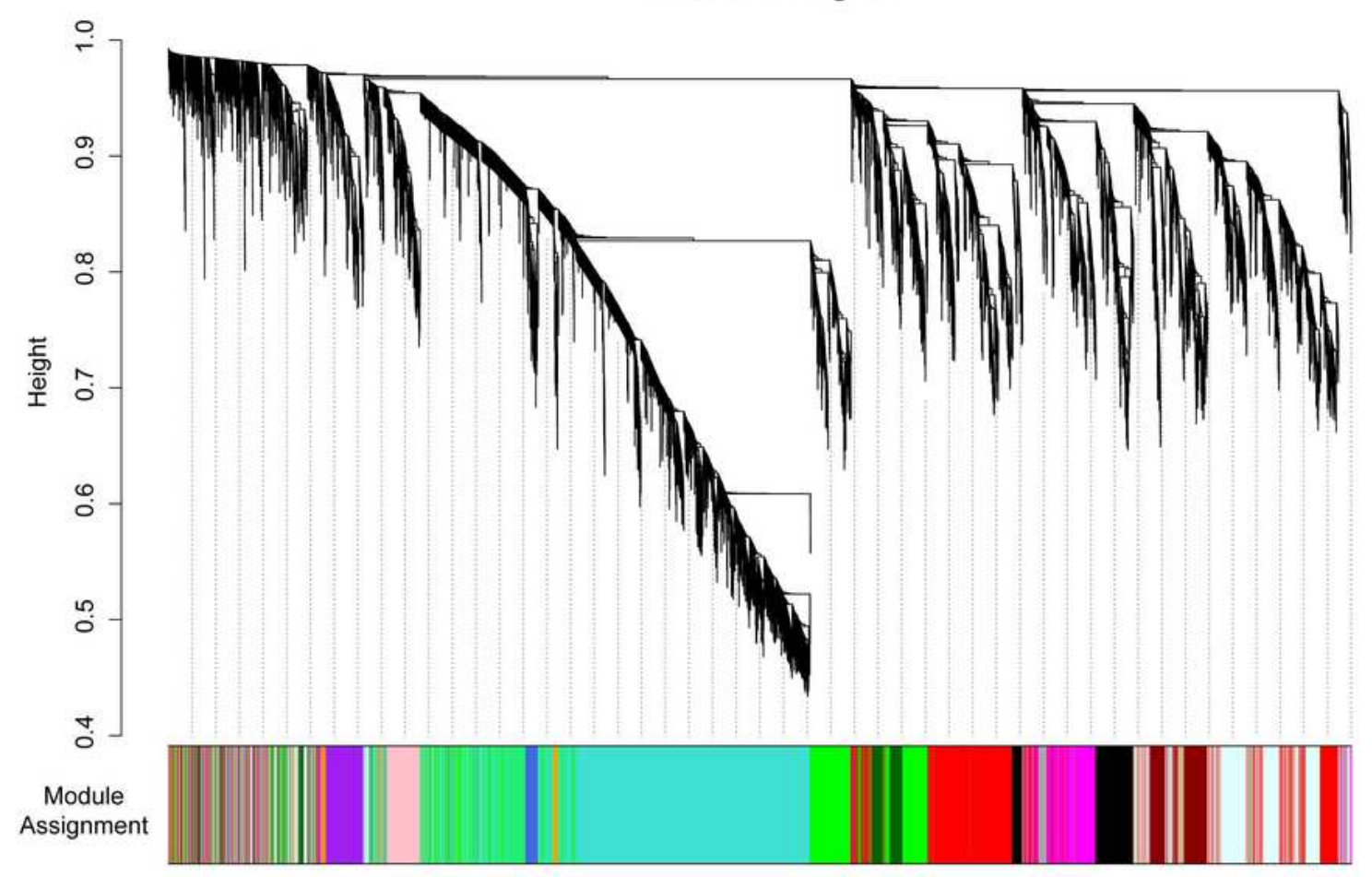

b

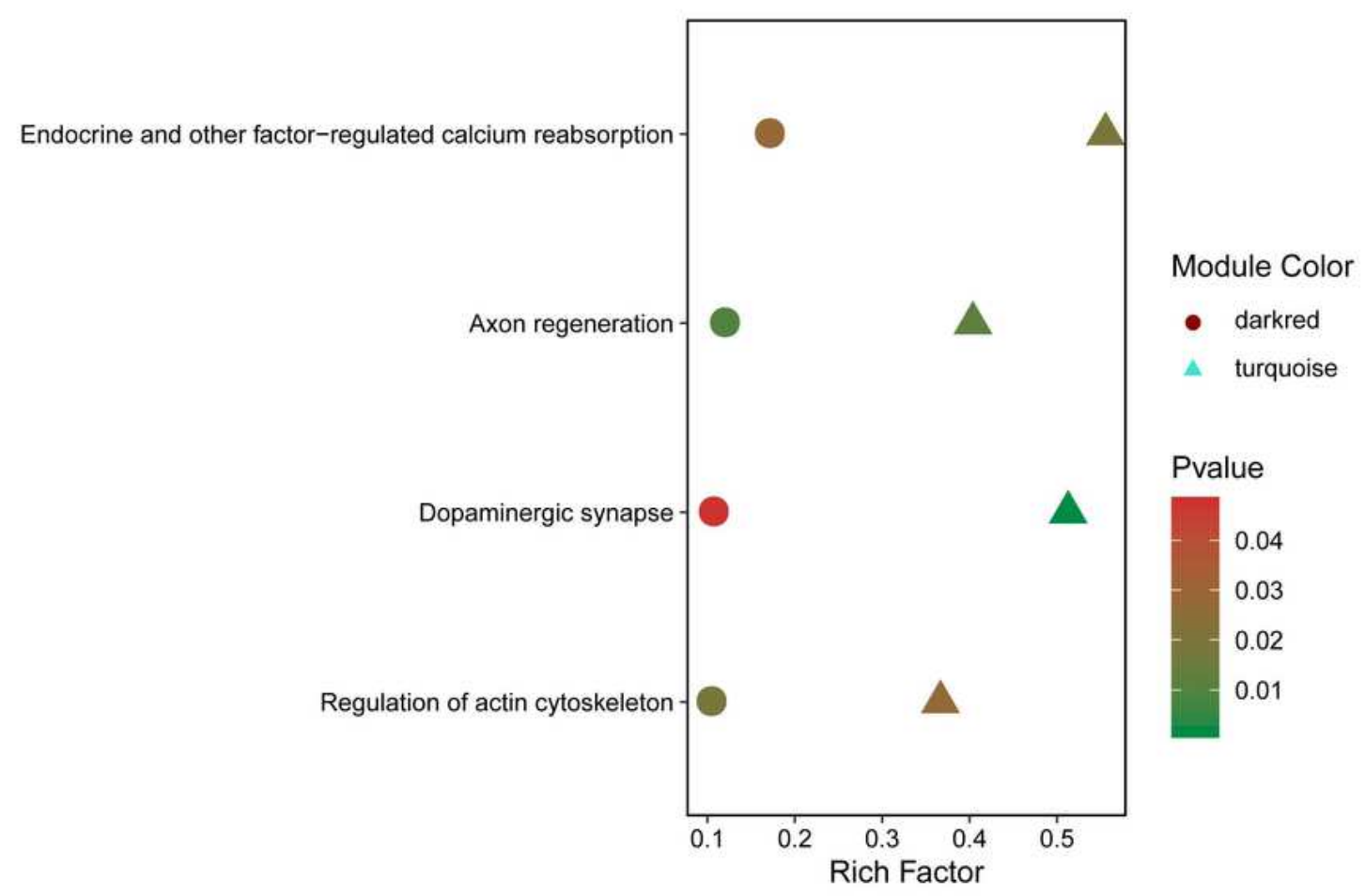

\section{Figure 3}

Identification of co expression genes related to candidate genes by Weighted gene co expression network analysis (WGCNA). a Hierarchical cluster tree showing the co expression modules identified by WGCNA. $b$ The overlapped pathways that are enriched for gene modules turquoise and dark red. 

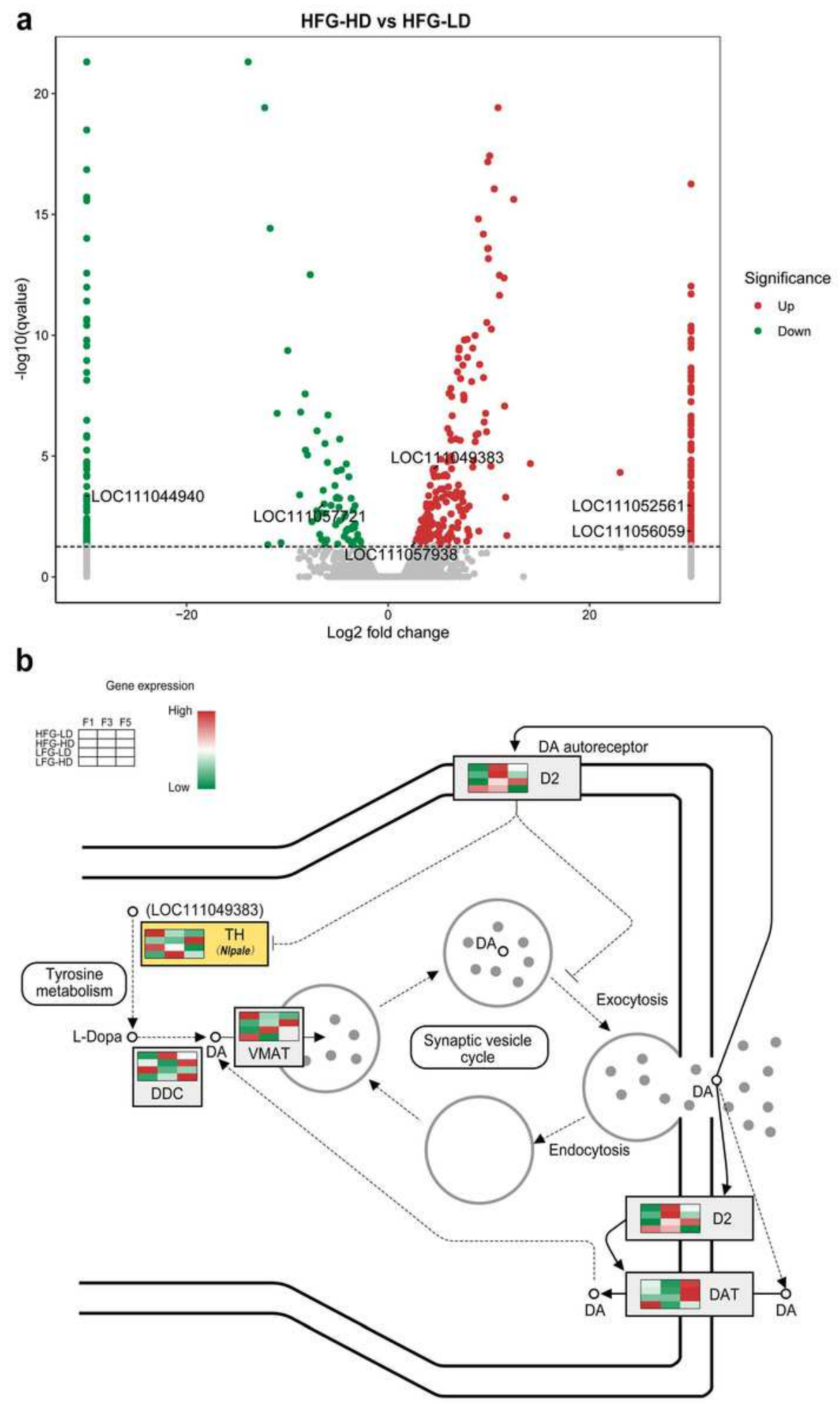

\section{Figure 4}

Targeting the key regulatory factors by differential expression analysis. a A volcano plot of the gene expression pattern between HFG HD and HFG LD at F5. The black, red and green points represent no difference in expression, up regulated genes and down regulated genes (FDR $\leq 0.05$, Benjamini and Hochberg adjustment). $b$ The pathway map of Dopaminergic synapse. The expression patterns of detected genes in this pathway are presented by heatmap. 
a

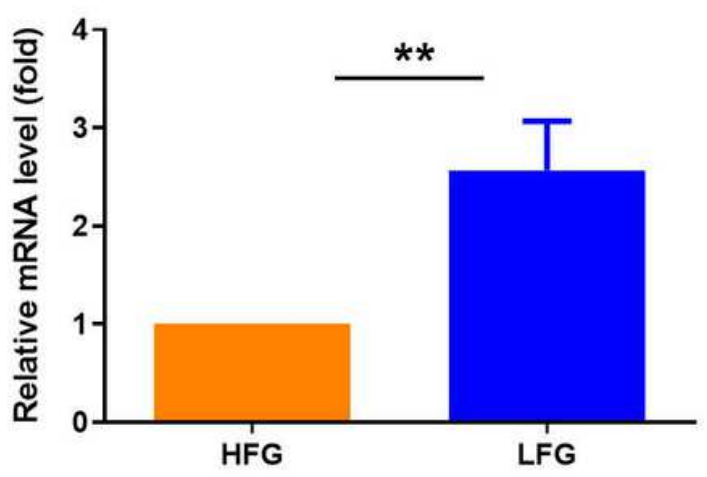

C

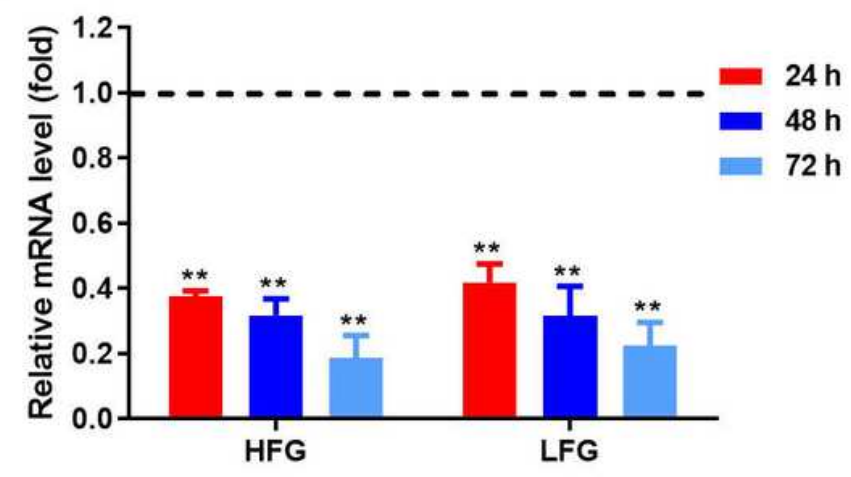

e

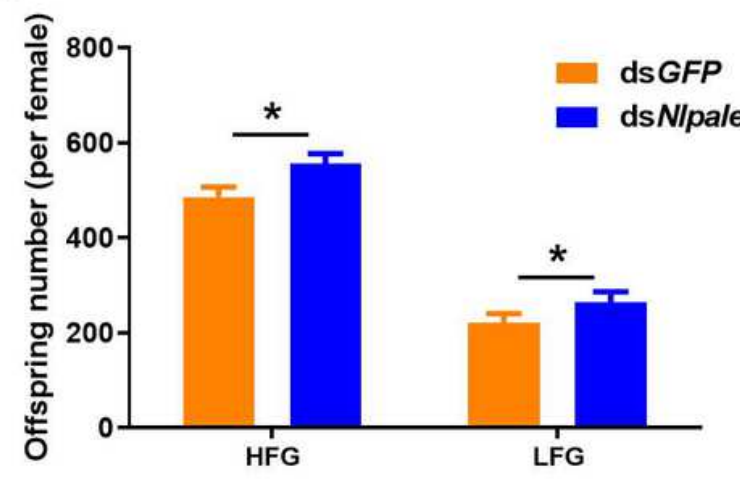

b

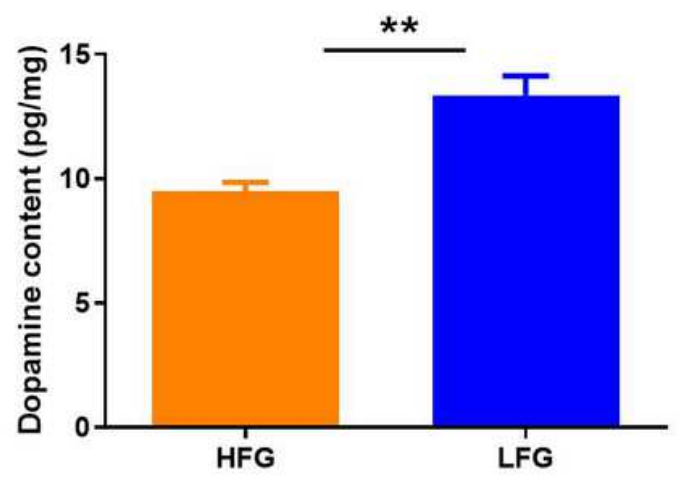

d

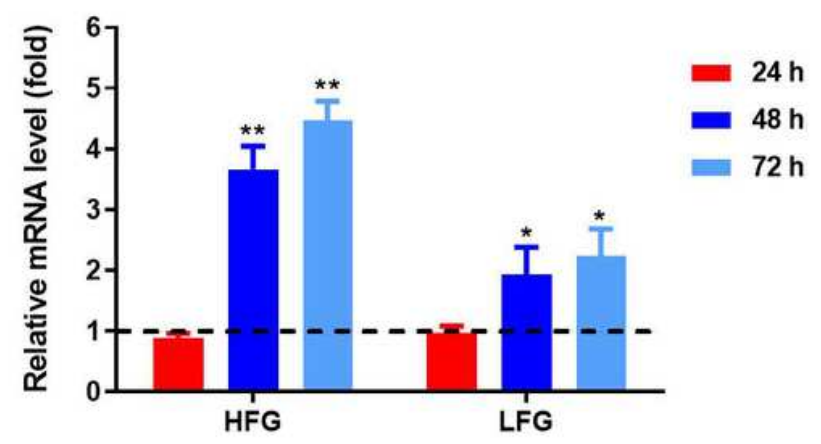

f

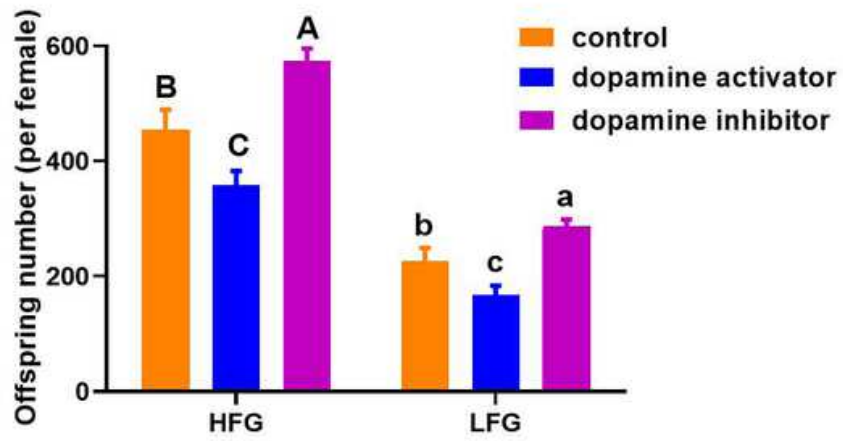

\section{Figure 5}

The role of Nlpale mRNA level and dopamine content in the fecundity of BPH. The Nlpale mRNA levels (a) and dopamine contents (b) in two genotypes insects are presented. The mRNA levels of Nlpale (c) and $\mathrm{NIVg}(\mathrm{d})$ in the two genotypes of BPH were measured at 24, 48 and $72 \mathrm{~h}$ after RNA interference of Nlpale. The insects injected with dsGFP were used as control. e The fecundity of HFG and LFG after injection of Nlpale dsRNA. $f$ The fecundity of HFG and LFG after injection of dopamine inhibitor chlorpromazine, dopamine hydrochloride (activator), and water control. All data are presented as mean \pm SE. *: $\mathrm{P}<0.05$ 
level; ${ }^{* *}: \mathrm{P}<0.01$ level (student's t test). The values sharing different letters are significantly different at $\mathrm{P}$ $<0.05$ (one way ANOVA and Duncan's multiple range test).

a

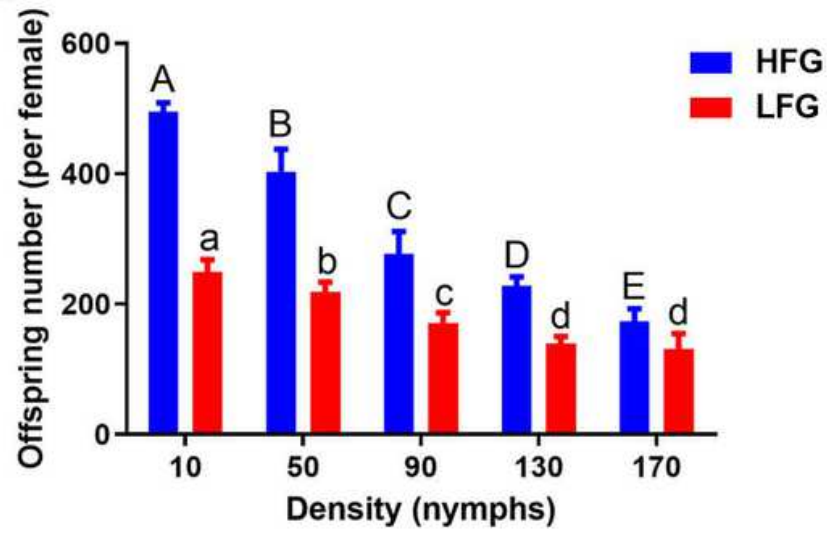

C

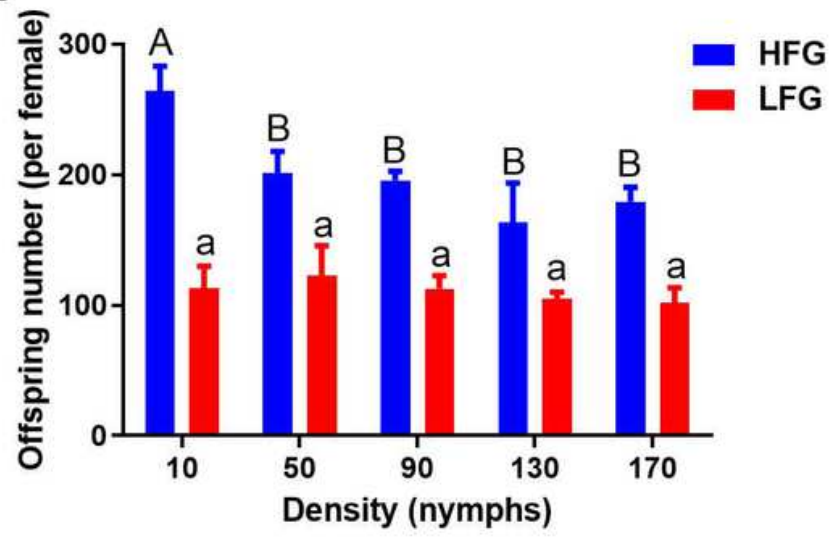

b

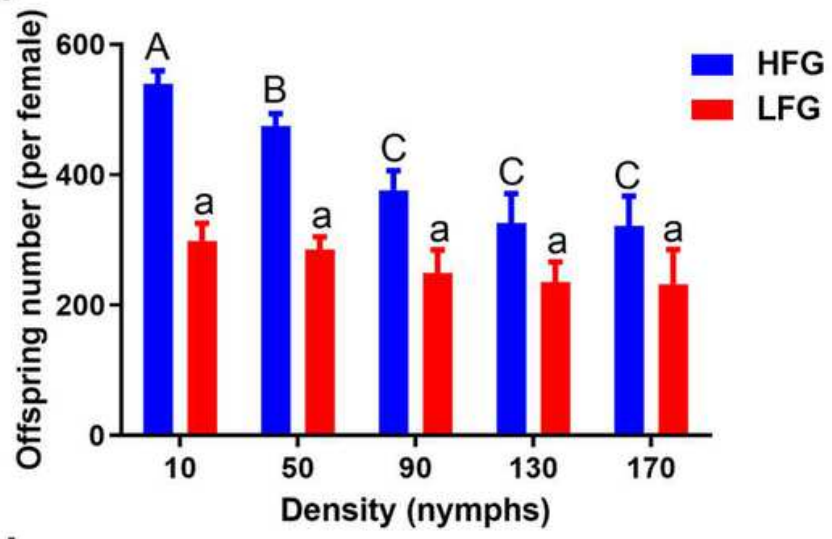

d

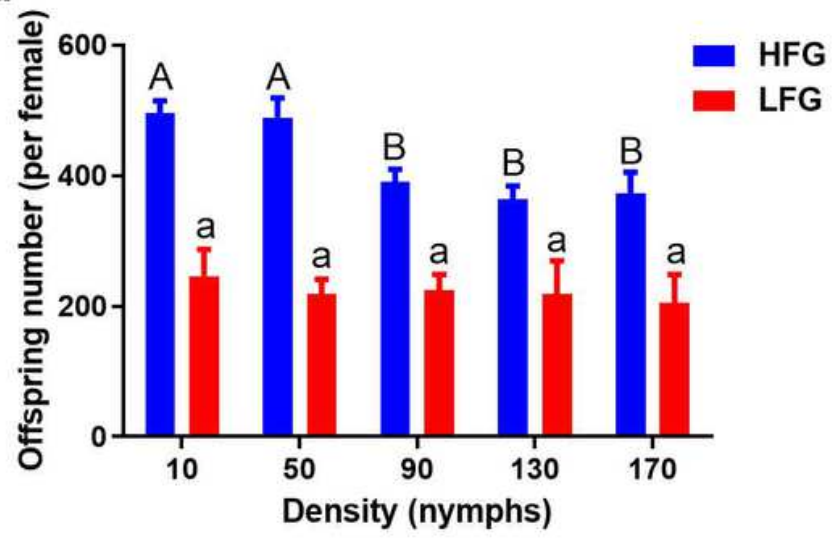

Figure 6

The role of dopamine biosynthesis in the density dependent effects on the fecundity of BPH. The impact of injection of dsGFP (a), dsNlpale (b), dopamine hydrochloride (c), andchlorpromazine (d) on the fecundity of two genotypes insects under the population densities of 10, 50, 90, 130 and 170 individuals. All data are presented as mean \pm SE. The values sharing different capital letters are significantly different at $P<0.05$ within the HFG, and the values sharing different lowercase letter are significantly different at $P$ $<0.05$ within the LFG (one way ANOVA and Duncan's multiple range test).

\section{Supplementary Files}

This is a list of supplementary files associated with this preprint. Click to download.

- FigS1.tif

- Figs2.tif

- TableS1.xIsx

- Tables2.xlsx

- TableS3.xlsx 
- Tables4.xlsx

- Tables5.xIsx

- TableS6.xlsx

- Tables7.xlsx

- Tables8.xlsx 